\title{
Analisis pergerakan tanah kelurahan aur mulyo dengan metode sig
}

\author{
Tri Gamela Saldy $1^{1)^{*}}$, Rizto Salia Zakri ${ }^{1)}$ \\ ${ }^{12}$ Jurusan Teknik Pertambangan, Universitas Negeri Padang, Padang, Indonesia. \\ trigamelasaldy@ft.unp.ac.id * ; riztoszakri@ft.unp.ac.id
}

\begin{abstract}
ABSTRAK
Kelurahan Aur Mulyo merupakan wilayah berupa dataran hingga perbukitan. Kelurahan ini sering mengalami longsor sehingga menimbulkan kerugian, baik kerugian harta benda maupun korban jiwa. Penelitian ini bertujuan untuk memberikan petunjuk kepada masyarakat sekitar berkaitan tentang potensi bahaya terhadap pergerakan tanah yang akan terjadi. Penelitian ini menggunakan metode SIG untuk mendapatkan peta kerentanan pergerakan tanah di daerah kelurahan Aur Mulyo. Berdasarkan model pergerakan tanah, wilayah Kelurahan Aur Mulyo berada pada wilayah berpotensi kerentanan pegerakan tanah rendah -sangat tinggi. Kawasan dengan berpotensi rendah berada pada daerah yang memiliki kontur cukup rata dan daerah berkontur curam berada pada daerah sekitar Puncak Polan, memiliki kerentanan sedang seluas 24,57 Ha dan kerentanan tinggi seluas $42,93 \mathrm{Ha}$, hal ini tergambarkan kepada faktor pengontrol pergerakan tanah.
\end{abstract}

Kata kunci: SIG, Kelurahan Aur Mulyo, Pergerakan tanah, Topografi

\section{ABSTRACT}

Aur Mulyo Village is an area in the form of plains to hills. This village often suffers landslides that cause losses of both property losses and fatalities. This research aims to provide guidance to the surrounding community regarding the potential dangers to land movements that will occur. This study used GIS to obtain a map of the vulnerability of land movement in the Aur Mulyo village area. Based on the soil movement model, the area of Aur Mulyo Village is in an area with low-very high potential for landslide susceptibility. Areas with low potential are in areas that have fairly flat contours and areas with steep contours are in the area around Puncak Polan, having moderate vulnerability of 24.57 hectares and high vulnerability of 42.93 hectares, this is illustrated by the factor controlling soil movement.

Keywords: GIS, Aur Mulyo Village, Ground Movement, Topography

diunggah: Desember 2021, direvisi: Desember 2021, diterima: Desember 2021, dipublikasi: Desember 2021 Copyright (c) 2021 Tri Gamela Saldy, Rizto Salia Zakri

This is an open access article under the CC-BY license

\section{PENDAHULUAN}

Gerakan tanah merupakan fenomena alam untuk mencapai kondisi baru. Gerakan tanah ini terjadi akibat terganggunya keseimbangan dari lereng. Lereng terganggu secara alamiah dan akibat ulah manusia. Bukit Polan berada pada Kelurahan Aur Mulyo, Kecamatan Lembah Segar, Kota sawahlunto, Provinsi Sumatera Barat. Luas Kelurahan Aur Mulyo adalah 0,20 kilometer persegi. Kelurahan Aur Mulyo terdiri dari 3 RW dan 6 RT. Penduduk Kelurahan Aur Mulyo berjumlah yaitu 993 jiwa (2017). Daerah ini memiliki potensi yang tinggi untuk terjadinya tanah longsor hal ini dikarenakan oleh kombinasi faktor alami. geologi maupun curah hujan). Kawasan ini dilalui oleh patahan (sesar) yang merupakan sesar ikutan (tangensial fault) dari sesar utama (main fault), dimana batupasir kuarsa terlihat mengalami breksiasi, yang berperan sebagai bidang gelincir dan rembesan (mata air) air di kala hujan. Disamping itu, curah hujan serta kemiringan lereng yang cukup tinggi merupakan salah satu faktor pemicu. Faktor aktifitas manusia seperti adanya pembuatan jalan menuju 
kawasan puncak Bukit Polan dan adanya bangunan villa/homestay serta aktifitas perladangan/perkebunan pada kawasan puncak bukit juga dapat memicu longsor susulan.

Secara umum masalah yang akan diidentifikasikan adalah sebagai berikut:

1. Berdasarkan kriteria yang digunakan, apakah tanah pada daerah penelitian aman dari potensi pergerakan/longsoran.

2. Daerah mana saja yang memiliki tingkat kerawanan pergerakan tanah sangat ringan-berat berdasarkan kriteria yang digunakan.

Penelitian ini masuk dalam skema penelitian dosen pemula dengan topik kajian mitigasi bencana, artinya penelitian lebih bersifat aplikasi dari teori yang ada, dalam hal ini metode sistem informasi geografis di terapkan pada kajian mitigasi bencana, sesuai dengan kriteria skema penelitian dosen pemula.

Gerakan tanah merupakan suatu gerakan perpindahan tanah atau massa batuan akibat adanya gaya gravitasi (gaya berat). Faktor - faktor dari penyebab terjadinya gerakan tanah adalah dari faktor geologi dan faktor non geologi

\section{METODE} kualitatif.

Penelitian menggunakan mix-methods yaitu gabungan dari pendekatan kuantitatif dan

Berikut merupakan tahapan dari penelitian (gambar 1).

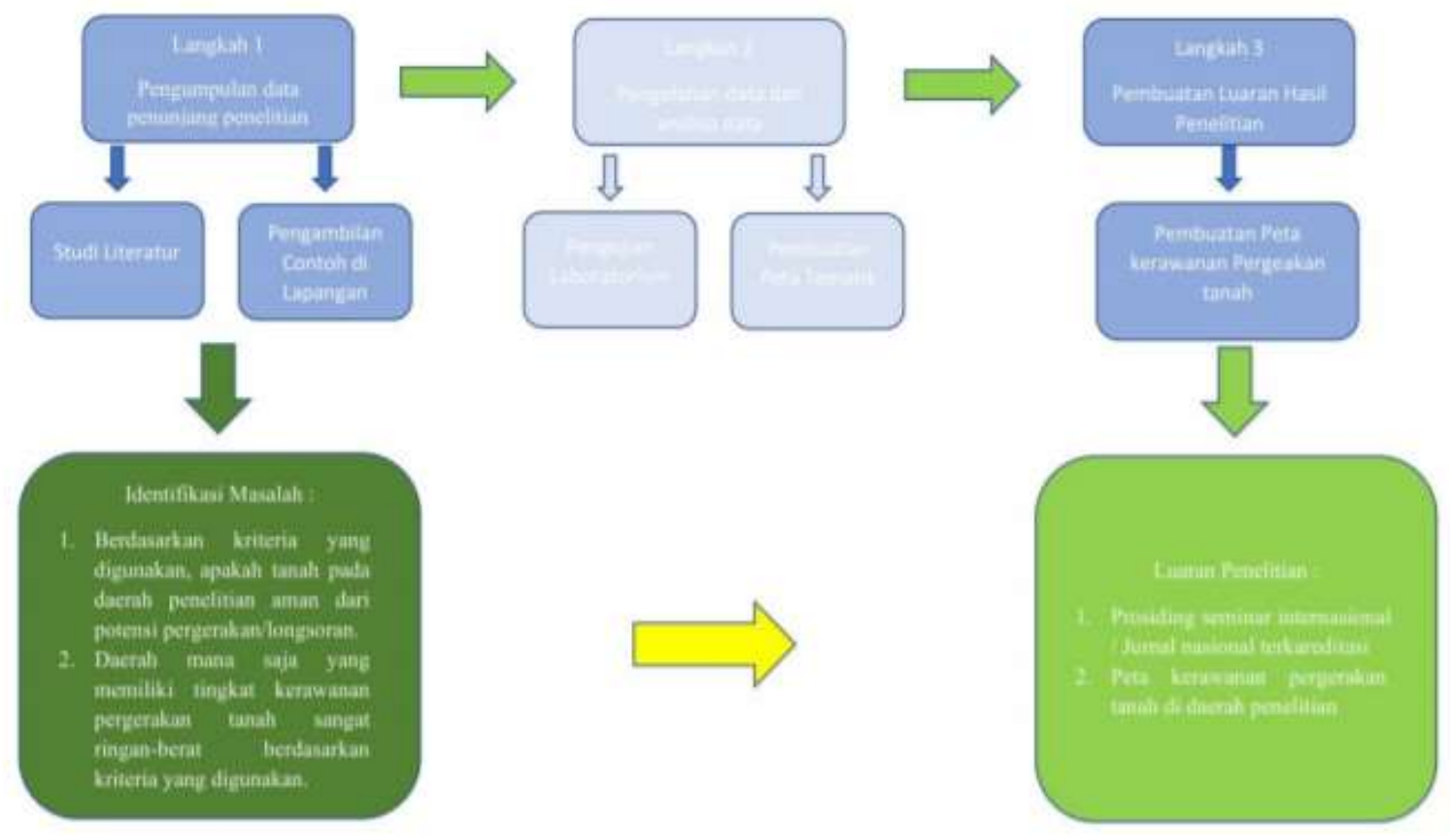

\section{Gambar 1. Diagram alir}

Penelitian ini menggunakan data primer dan data sekunder. Data primer dari lapangan adalah data yang diambil dari pengukuran strike dan dari pengukuran dip, pengukuran geometri lereng longsor, beserta koordinat lokasi longsor di lapangan serta data sampel tanah sekitar 4 (empat) titik di lokasi penelitian. Data sekunder yang diambil seperti peta geologi, peta kemiringan lereng, peta topografi, peta tata guna lahan, peta curah hujan dan peta jenis tanah.

Diperlukan data-data yang mendukung untuk proses pengolahan data spasial. Data spasial yang digunakan yaitu data analog (Peta Jenis Tanah, Peta Geologi dan Peta Jenis 
Penutupan Lahan) dan data digital (Peta Jenis Batuan, Peta Zona Kerentanan Gerakan Tanah dan Peta Kemiringan Lahan).

Setiap data pada tahap awal akan dijadikan peta digital. Peta yang ada pada data analog akan diolah menjadi peta digital dengan format vektor. Data - data ini diproses dengan menggunakan software Arcgis 10.4.1.

Ada beberapa faktor pengontrol dalam menentukan bobot dan skor dalam kerentanan gerakan tanah yaitu curah hujan, kemiringan lereng dan tataguna lahan, jenis tanah dan jenis batuan seperti pada tabel 1 .

Tabel 1. Parameter faktor pengontrol

\begin{tabular}{|c|c|c|c|c|}
\hline No. & \begin{tabular}{c|c|} 
Faktor \\
Pengontrol
\end{tabular} & Parameter & Bobot & Skor \\
\hline \multirow{5}{*}{1} & \multirow{5}{*}{ Curah Hujan } & Sangat Basah $(>3000)$ & \multirow{5}{*}{$30 \%$} & 5 \\
\hline & & Basah (2501-3000) & & 4 \\
\hline & & Sedang (2001-2500) & & 3 \\
\hline & & Kering (1501-2000) & & 2 \\
\hline & & Sangat Kering $(<1500)$ & & 1 \\
\hline \multirow{7}{*}{2} & \multirow{7}{*}{$\begin{array}{c}\text { Kemiringan } \\
\text { Lereng }\end{array}$} & $>140$ & \multirow{7}{*}{$20 \%$} & 5 \\
\hline & & $56-140$ & & 4 \\
\hline & & $21-55$ & & 3 \\
\hline & & $14-20$ & & 2 \\
\hline & & $8-13$ & & 1 \\
\hline & & $3-7$ & & 1 \\
\hline & & $<2$ & & 1 \\
\hline \multirow{5}{*}{3} & \multirow{5}{*}{$\begin{array}{c}\text { Tataguna } \\
\text { Lahan }\end{array}$} & Tegalan, sawah & \multirow{5}{*}{$20 \%$} & 5 \\
\hline & & Semak belukar & & 4 \\
\hline & & Hutan dan perkebunan & & 3 \\
\hline & & Kota/pemukiman & & 2 \\
\hline & & Tambak,waduk,perairan & & 1 \\
\hline \multirow{5}{*}{4} & \multirow{5}{*}{ Jenis Tanah } & Regosol & \multirow{5}{*}{$10 \%$} & 5 \\
\hline & & Andosol, podsolik & & 4 \\
\hline & & Latosol coklat & & 3 \\
\hline & & Asosiasi latosol coklat kekuningan & & 2 \\
\hline & & Aluvial & & 1 \\
\hline \multirow{3}{*}{5} & \multirow{3}{*}{ Jenis Batuan } & Batuan vulkanik & & 3 \\
\hline & & Batuan sedimen & $20 \%$ & 2 \\
\hline & & Batuan aluvial & & 1 \\
\hline
\end{tabular}

Sumber: Riki Rahmad (2008)

Klasifikasi bagaimana kelas kerawanannya dilihat pada tabel 2 .

Tabel 2. Interval skor kelas kerawanan

\begin{tabular}{|c|c|}
\hline Interval Skor (\%) & Kelas Kerawanan \\
\hline $1,7-2,024$ & Rendah \\
\hline $2,025-2,349$ & Sedang \\
\hline $2,35-2,674$ & Tinggi \\
\hline $2,675-3$ & Sangat Tinggi \\
\hline
\end{tabular}




\section{HASIL DAN PEMBAHASAN}

Dari pengumpulan data lapangan dan hasil studi peta maka akan didapatkan beberapa peta. Berberapa peta tersebut meliputi:

1. Peta Jenis Batuan Wilayah Kelurahan Aur Mulyo.

Jenis batuan pada Kelurahan Aur Mulyo didominasi oleh batu tupa, lanau dan lempung seluar 96,70 Ha (gambar 2).

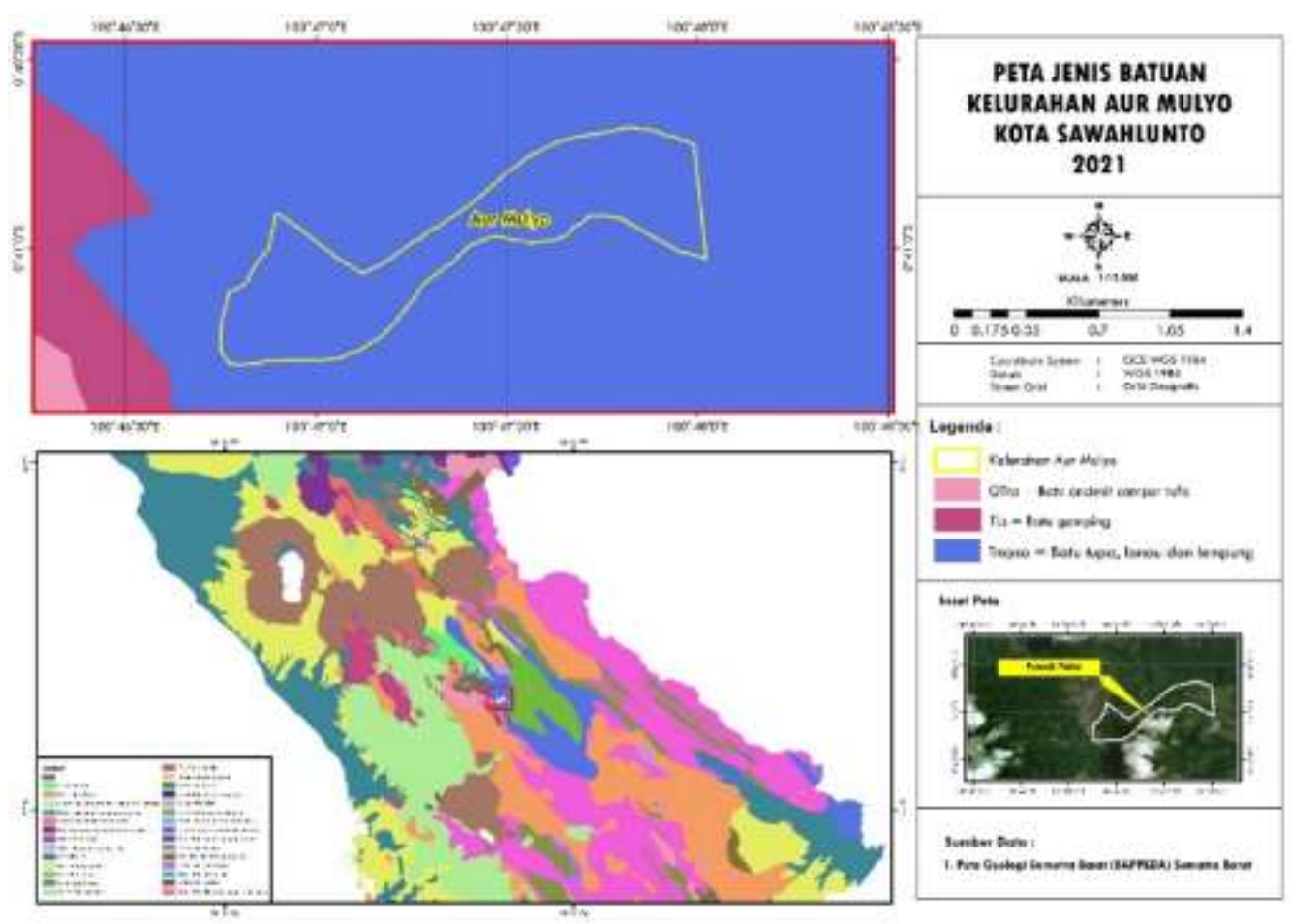

Gambar 2. Peta jenis tanah wilayah kelurahan aur mulyo

2. Peta Curah Hujan Kelurahan Aur Mulyo

Curah hujan pada kelurahan aur mulyo sebesar 1500 - 2000 mm dengan luas 96,70 Ha. Peta curah hujan Kelurahan Aur Mulyo dapat dilihat pada gambar berikut.

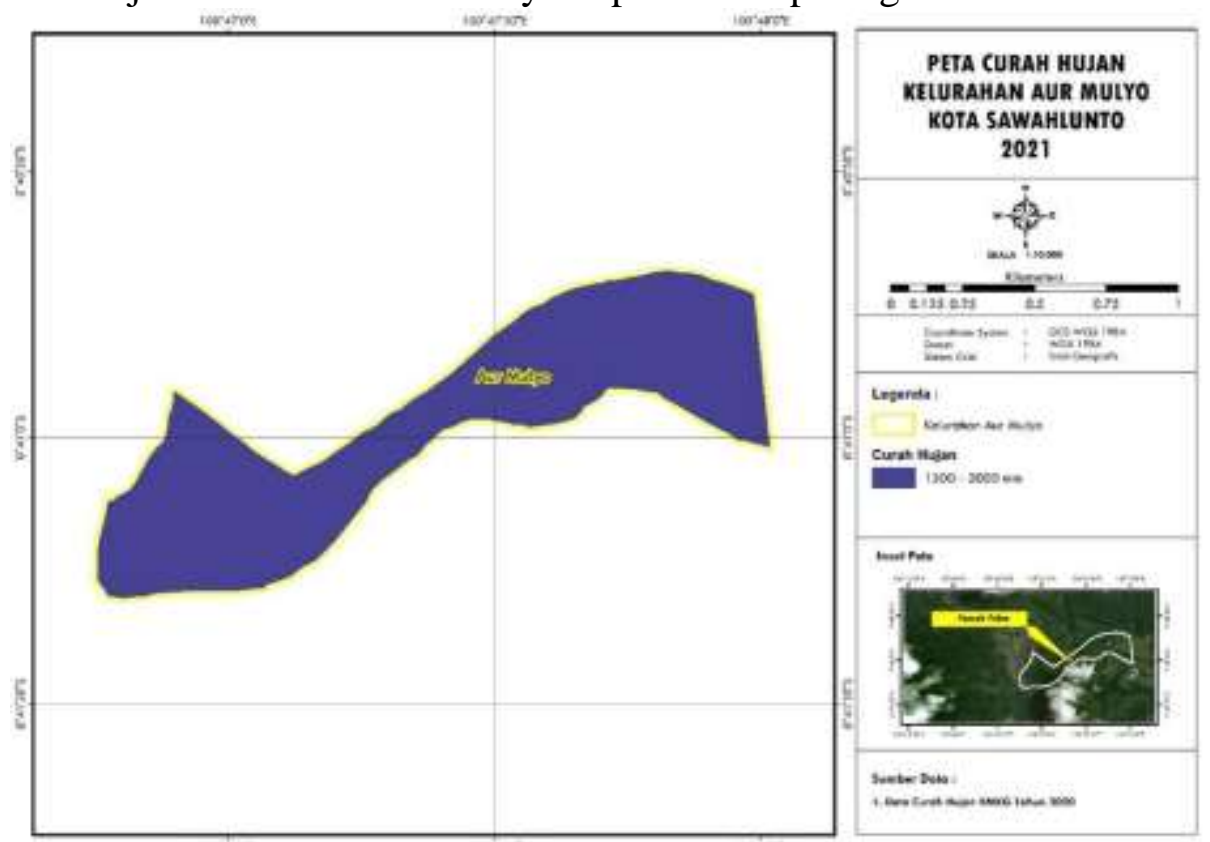

Gambar 3. Peta curah hujan kelurahan aur mulyo 
3. Peta Jenis Tanah Kelurahan Aur Mulyo

Jenis tanah dari Kelurahan Aur Mulyo adalah Glei humus 19,83 Ha dan didominasi oleh podsolik seluas 76,87 $\mathrm{Ha}$ (gambar 4).

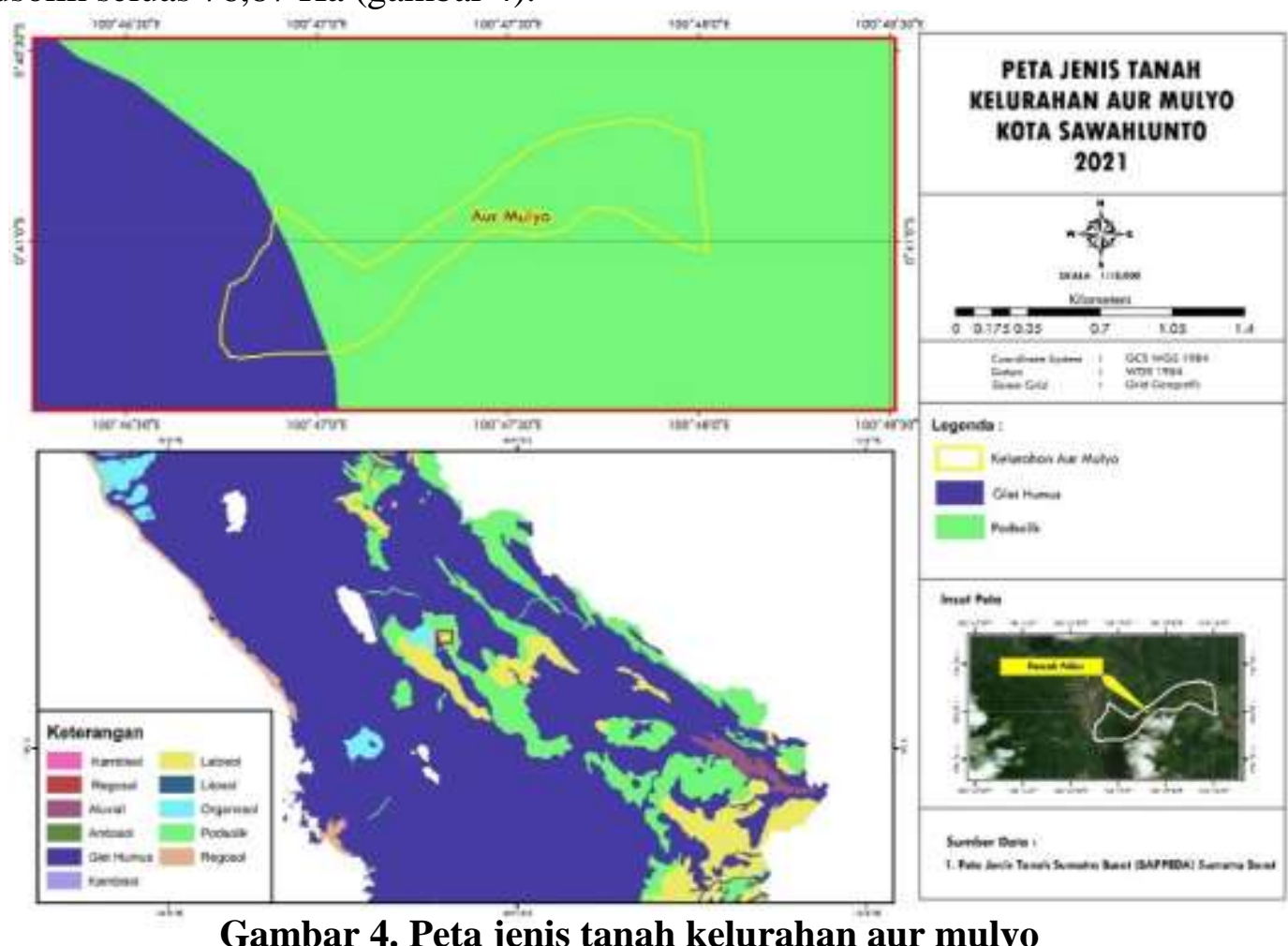

4. Peta Kemiringan Lereng Kelurahan Aur Mulyo

Kemiringan lereng Kelurahan Aur Mulyo yaitu berada pada agak curam sampai dengan sangat curam (gambar 5)
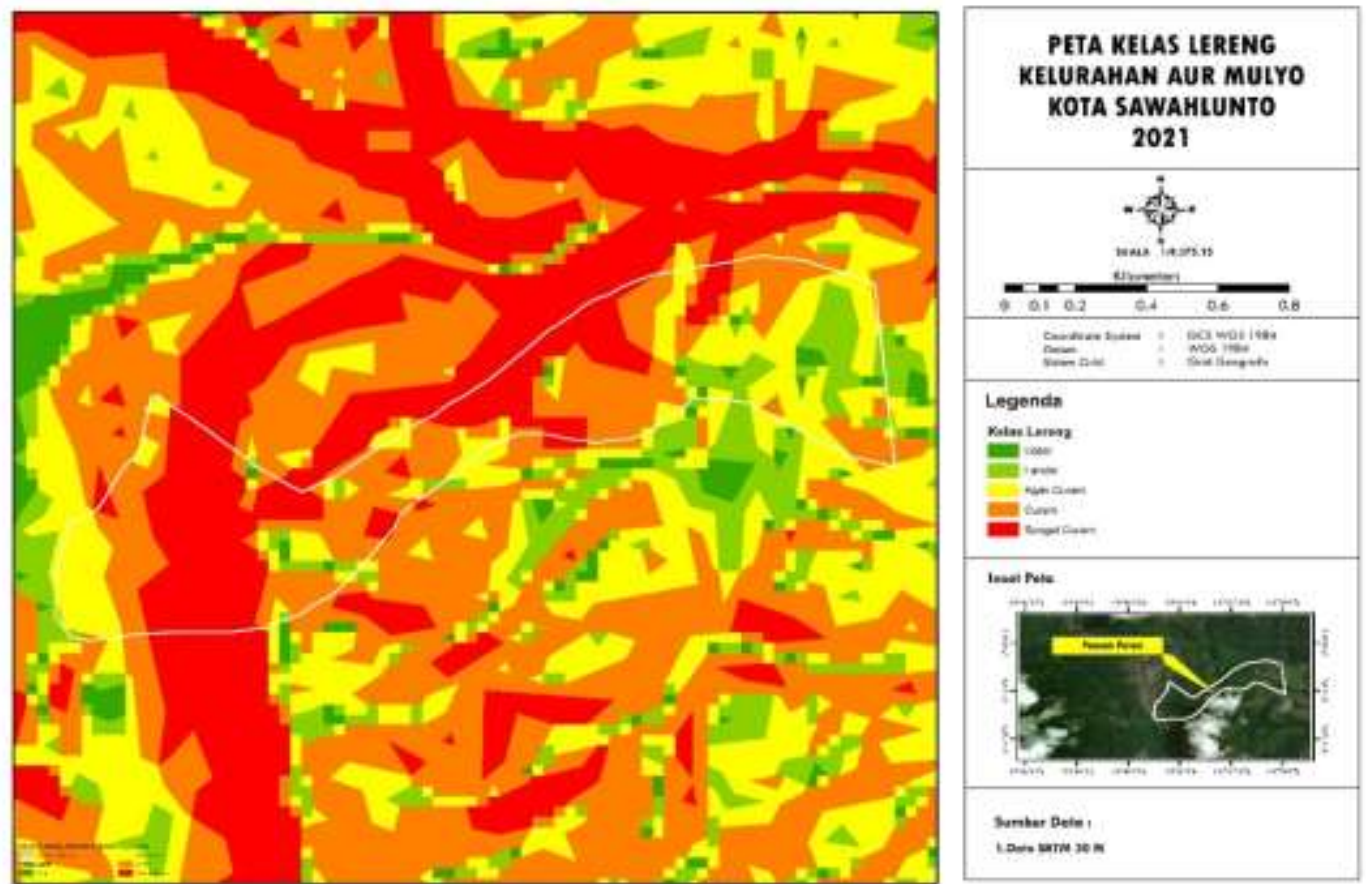

Gambar 5. Peta kemiringan lereng kelurahan aur Mulyo 
5. Peta Tataguna Lahan Kelurahan Aur Mulyo

Lahan yang berada pada Kelurahan Aur Mulyo adalah hutan lahan kering sekunder/ bekas tebangan seluas 4,88 Ha, Ladang seluas 71,21 Ha, Pemukiman/lahan terbangun seluas 12,54 Ha dan semak belukar seluas 8,07 Ha (gambar 6).

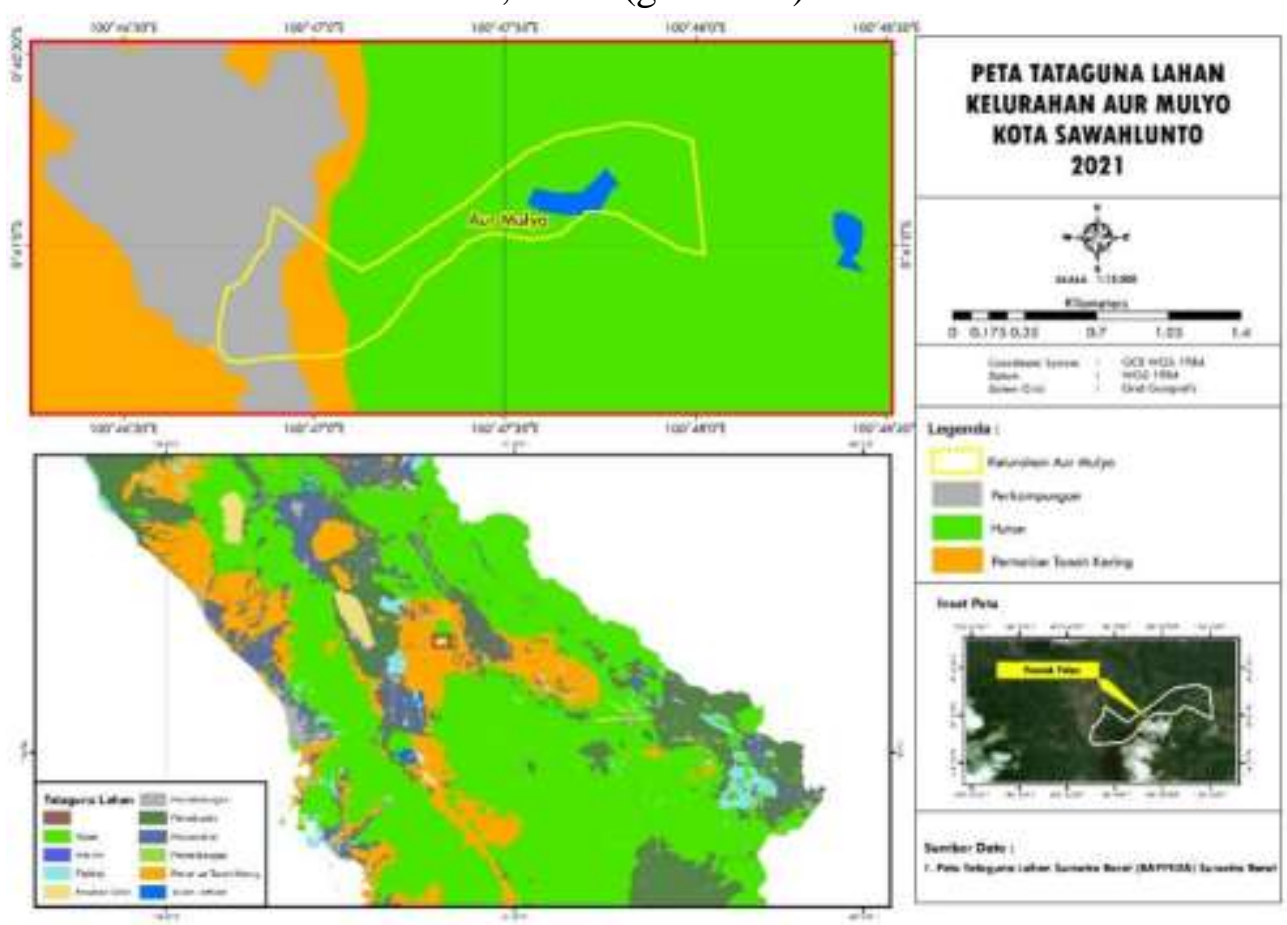

Gambar 6. Peta tataguna lahan kelurahan aur mulyo

Dari peta - peta yang sudah didapatkan maka akan dilakukan overlay, sehingga didapatkan Peta Zona Kerentanan Tanah Kelurahan Aur Mulyo (gambar 7). Kerawanan gerakan tanah di Kelurahan Aur Mulyo adalah kerawanan rendah dengan luas 5,50 Ha, kerawanan sedang seluas 24,57 Ha, kerawanan tinggi seluas 42,93 Ha, dan kerawanan sangat tinggi seluas $20,10 \mathrm{Ha}$.

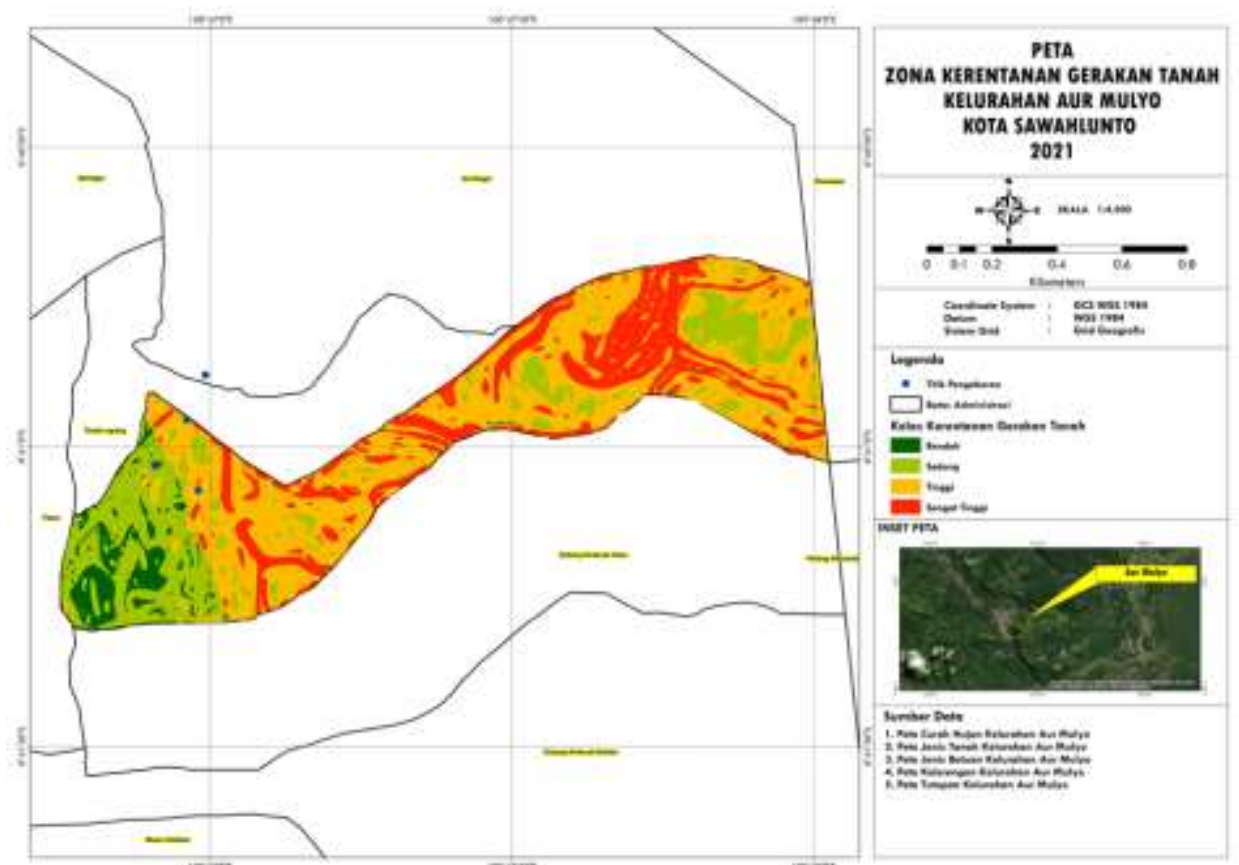

Gambar 7. Peta zona kerentanan tanah kelurahan aur mulyo 


\section{SIMPULAN}

Dari peta zona kerentanan tanah Kelurahan Aur Mulyo didapat bahwa: Kerentanan tanah Kelurahan Aur Mulyo berada pada kelas tinggi - sangat tinggi dengan artian daerah ini sangat rentan terhadap pergerakan tanah dan sudah sering terjadi gerakan - gerakan tanah.

\section{DAFTAR PUSTAKA}

Alivia Desi Anita Kusuma Ningtyas, dkk. 2013. Analisa Tingkat Pergerakan Tanah Di Areal Tambang Terbuka Ditinjau Dari Survey Terestris dan Data Geologi, Teknik Geomatika, Fakultas Teknik Sipil dan Perencanaan, Institut Teknologi Sepuluh November, Surabaya. http://digilib.its.ac.id/public/ITSpaper-30004-3509100045Paper.pdf. (08/02/2020).

Ardi Chandra Yunianto. 2011. Skripsi Analisis Kerawanan Tanah Longsor Dengan Aplikasi Sistem Informasi Geografis (Sig) Dan Penginderaan Jauh Di Kabupaten Bogor, Fakultas Kehutanan, Institut Pertanian Bogor. https://anzdoc.com/queue/analisiskerawanan-tanah-longsor dengan-aplikasisisteminfo.html, (20/02/2020).

Arif Irwandy. 2016. Geoteknik Tambang (Mewujudkan Produksi Tambang yang Berkelanjutan dengan Menjaga Kestabilan Lereng. Jakarta: Gramedia Pustaka Utama (Anggota IKAPI)

Badan Standarisasi Nasional, Standar Nasional Indonesia (SNI). 2005. Penyusunan Peta Zona Kerentanan Gerakan Tanah, https://kupdf.net/download/sni- penyusunanpetazona-kerentanangerakantanah_58e268d7dc0d60f40c89 7108_pdf. (20/02/2020).

Dinas Geologi Sumberdaya Mineral. 2015. Dokumen Dinas Energi dan Sumber Daya Mineral (ESDM) Pemprov Sumatera Barat. Padang.

Hary Christady Hardiyatmo. 2010. Mekanika Tanah 1 Edisi V, Universitas Gadjah Mada. Yogyakarta.

Hary Christady Hardiyatmo. Penanganan Tanah Longsor dan Erosi, Gadjah Mada University Press, Yogyakarta. 2006.

Ike Bermana. 2006. Klasifikasi Geomorfologi Untuk Pemetaan Geologi Yang Telah Dibakukan, Jurusan Geologi, FMIPA, Universitas Padjadjaran, Bandung. http://jurnal.unpad.ac.id/bsc/article/vie w/8125. (01/02/2020).

Mahdi Yono. Analisis Gerakan Tanah Dengan Menggunakan Metode Sistem Informasi Geografis (Sig) Di Daerah Iup Pt. Bintang Sumatera Pacific, Kecamatan Pangkalan Koto Baru, Kabupaten Lima Puluh Kota, Provinsi Sumatera Barat.

Sekolah Tinggi Teknologi Insdustri. Padang. 2019. Maiyudi, R., Anaperta, Y. M., Ramadhan, F. R., Saldy, T. G., Rahman, H. A., \& Zakri, R. S. PKM Pelatihan Mitigasi Bencana Alam bagi Siswa SMAN 3 Solok. Bina Tambang, 4(3), 385-394. 2019. 
Riki Rahmad, Suib dan Ali Nurman. Aplikasi SIG Untuk Pemetaan Tingkat Ancaman di Kecamatan Sibolangit, Kabupaten Deli Serdang, Sumatera Utara. Pendidikan Geografi, Fakultas Ilmu Sosial, Universitas Negeri Medan, Medan.

2018.https://www.researchgate.net/publication/325318418_Aplikasi_SIG_Un tuk_ Pemetaan Tingkat_Ancaman_Longsor_Di_Kec amatan_Sibolangit_Kabupaten_Deli__Serdang_S umatera_Utara/download. (08/02/2018).

Saldy, T. G., \& Zakri, R. S. 2021. ANALISIS PERGERAKAN TANAH KECAMATAN PADANG SELATAN DENGAN METODE SISTEM INFORMASI GEOSPASIAL (SIG). Jurnal Sains dan Teknologi: Jurnal Keilmuan dan Aplikasi Teknologi Industri, 20(2), 246-252.

Saldy, T. G., Maiyudi, R., Anaperta, Y. M., Rahman, H. A., \& Zakri, R. S. 2020. PKM Sosialisasi Mitigasi dan Kesiapsiagaan Bencana Alam di SMA N 2 Kota Solok. Bina Tambang, 5(3), 78-87.

Yogi Saktyan Respati, dkk. 2010. Analisis GIS Terhadap Gerakan Tanah di Girimulyo, Kulonprogo, D.I. Yogyakarta, dan Kajian Faktor - Faktor Pengontrolnya. Geological Engineering Department. Gadjah Mada University. Yogyakarta. .. http://hmtg.ft.ugm.ac.id/web/wpcontent/uploads/Analisis-GISTerhadapGerakanTanah-di Girimulyo.pdf, 08/02/2020.

Zakri, R. S., Prengki, I., \& Saldy, T. G. 2020. Hubungan Kuat Tekan Uniaksial dan Kuat Tarik Tidak Langsung Pada Batuan Sedimen Dengan Nilai Kuat Tekan Rendah. Bina Tambang, 5(3), 59-70.

Zakri, R. S., Prengki, I., \& Saldy, T. G. Relationship between Uniaxial Compressive Strength and Indirect Tensile Strength on Sedimentary Rocks with Low Compressive Strength. 